\title{
Conditioned aversion to morphine with lithium chloride in morphine-dependent rats
}

\author{
B. FERNANDEZ and J. W. TERNES \\ Caribbean Primate Research Center, University of Puerto Rico \\ Sabana Seca, Puerto Rico 00794
}

\begin{abstract}
Two groups of 180-day-old male Wistar rats which had learned to drink morphine solution in order,to avoid withdrawal stress received two separate pairings of morphine taste with either IP injection of LiCl or physiological saline. A two-bottle extinction test between morphine solution and tap water was given on the day separating the two conditioning trials and for 4 days following the second conditioning trial. An ANOVA indicated no significant main effects; however, the Groups by Days interaction was significant. Tests of simple main effects of groups were significant on the days following each conditioning trial. Thus, long-term familiarity with the test substance did not block conditioning. The results are discussed as an example of prepared learning.
\end{abstract}

Bolles (1972) has suggested the existence of an innate recognition mechanism which precluded the necessity of learning a preference for special food flavors that satisfy most naturally occurring need states. However, Parker, Failor, and Weidman (1973) demonstrated acquired preferences for a novel flavor associated with beneficial postingestional consequences when morphine withdrawal was the relevant need state. They suggest that, with unnatural need states, there exists no such innate recognition mechanism for repletion. A striking example of this can be seen in the work of Stolerman and Kumar (1970). They repeatedly gave both morphine and quinine solutions to thirsty rats. Initial aversions for bitter morphine were converted into preferences while consumption of bitter quinine was unaffected. The authors suggested that relief from thirst, a natural need state, did not accout for the acquired preference for morphine, whereas, relief from withdrawal stress, an unnatural need state, was apparently responsible.

Ternes (in press) demonstrated that rats forced to drink weak solutions of morphine during a 12-week period will subsequently self-administer morphine by drinking it in preference to water when both are made concurrently available. This acquired preference for morphine has been interpreted as evidence of morphine dependency. The long induction period suggests that rats are relatively unprepared to learn to associate the bitter taste of morphine with the beneficial postingestional consequences of relief from withdrawal stress.

The purpose of the present experiment was to test the hypothesis that conditioned aversion (Garcia, Kimeldorf, \& Koelling, 1955) can be used as a method for weaning morphine dependent rats from their drug. We here present data suggesting that short-term aversions to morphine taste were produced in dependent rats which had previously learned to drink weak morphinized

This research is based on a Master's thesis submitted to the University of Puerto Rico by the first author under the direction of the second author. Reprints may be obtained from $J$. W. Ternes, Department of Psychology, Rio Piedras, Puerto Rico. solutions in order to avoid withdrawal stress.

\section{METHOD}

\section{Subjects}

Subjects were 10 male Wistar rats which were morphine dependent. Throughout the experiment, the subjects were housed in standard Hoeltge wire rat cages in an open-air animal shelter at the Caribbean Primate Research Center, Sabana Seca, Puerto Rico.

\section{Procedure}

The dependency induction and preference test procedure has been described elsewhere (Ternes, in press). Basically, the induction procedure involved providing subjects with a solution of $.3 \mathrm{mg}$ morphine sulphate per milliliter of tap water as the only source of liquid for 84 days. Preference for morphine solution over water in an 8-day two-bottle preference test was interpreted as evidence that morphine dependence had been acquired.

Immediately following the preference test subjects were randomly assigned to two groups of five rats each. The first day of the experiment subjects were weighed and deprived of food and liquid for $8-\mathrm{h}$. Subsequently a $.3 \mathrm{mg} / \mathrm{ml}$ morphinized solution was placed on each cage. Two hours later the experimental subjects were injected intraperiotoneally (IP) with a .15-M solution of lithium chloride $(\mathrm{LiCl})$ equivalent to $2 \%$ of subject's body weight. Control subjects were injected with equivalent doses of physiological saline. One hour after injection the morphine solution was removed from the cages. Subjects were deprived until the following morning when they were provided with food and liquid for $1-\mathrm{h}$. Subsequently they were deprived until 4:00 p.m. that day when a two-bottle extinction test between $.3 \mathrm{mg} / \mathrm{ml}$ morphinized solution and water was initiated. The following day, the same deprivation, conditioning deprivation sequence was repeated. Following the second conditioning trial, extinction testing was continued for 4 consecutive days. Thus, there was a total of 5 days of extinction testing, with the first day separating the 2 conditioning trial days. Data from the five postconditioning extinction tests were converted into daily morphine preference scores by determining the percentage of the total liquid consumption (morphine + water) that was morphine during each 24 -h period. The data from the first extinction test, i.e., the test given on the day following the first conditioning trial, was included in the analysis. 


\section{RESULTS}

A 2 by 8 analysis of variance (ANOVA) with repeated measures on the second factor (Winer, 1962) indicated that there were no significant differences between the two groups prior to conditioning. Figure 1 (left panel) shows the profile of the preconditioning group morphine scores.

A separate 2 by 5 ANOVA with repeated measures on the second factor was performed on the postconditioning data. The main effects of groups $(\mathrm{F}=$ 2.26, $\mathrm{df}=1 / 8, \mathrm{p}>.17)$ and of days $(F=1.9, \mathrm{df}=4 / 32$, $\mathrm{p}>.13)$ were not significant. The Groups by Days interaction was significant $(F=3.276$, $d f=4 / 32$, $\mathrm{p}<.024$ ). Figure 1 (right panel) shows the profile of the postconditioning group morphine scores. The $\mathrm{LiCl}$ group is consistently lower than the saline group, with the largest differences occurring on the days following the two conditioning trials. In tests of simple main effects, groups were significant only on Day $1(\mathrm{p}<.01)$ and Day $2(\mathrm{p}<.05)$.

\section{DISCUSSION}

The significant Groups by. Days interaction indicates a transient conditioning effect which extinguished within 4 days. Figure 1, the profile of the daily group means, shows that the averison was observable only on the day after each of the two conditioning trials.

Typically. gustatory conditioning produces aversions to novel taste stimuli. Familiarization with the test substance is usually thought to attenuate the aversion. Elkins (1973) for example, manipulated flavor availability prior to conditioning and obtained a graded effect upon both acquisition and resistance to extinction with 20 days of preconditioning exposure being sufficient to completely block aversion formation. In the present experiment, subjects had daily experience with the test solution over a 3-month period and, because of their dependency upon this solution for the maintenance of their habit, ingested significant quantities of it every day. Thus, the conditioning of an aversion after such long familiarization with the test flavor suggests that rats are highly prepared to make the association of bitter morphine taste with illness, the attenuating effects of familiarity not withstanding.

The dire consequence which morphine abstinence represents to the dependent organism would further explain the transitory nature of the aversion in the present study. Seldom has a

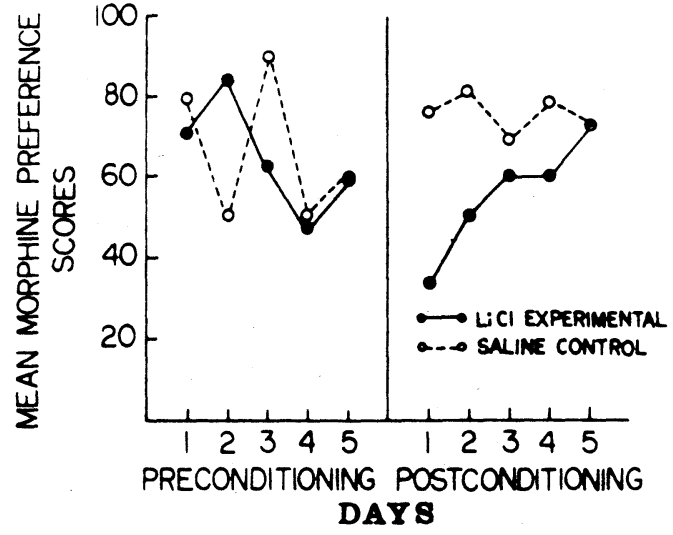

Figure 1. Group mean preferences for morphine prior to conditioning (left panel) and following conditioning (right panel).

conditioned aversion been placed under such extreme pressure to extinguish in a two-bottle preference test. According to Wikler (1953) maximum withdrawal stress occurs between $48-\mathrm{h}$ and 96-h after the last dose of morphine. Since extreme withdrawal stress is probably more aversive than conditioned $\mathrm{LiCl}$ illness. it is not surprising that the aversions were completely extinguished in all subjects within 4 days of the final conditioning trial.

\section{REFERENCES}

Bolles, R. C. Reinforcement, expectancy, and learning. Psychological Review, 1972, 79, 394-410.

Elkins, R. L. Attenuation of drug-induced bait shyness to a palatable solution as an increasing function of its availability prior to conditioning. Journal of Behavioral Biology, 1973, 9, 221-226.

Garcia, J., Kimeldorf, D. J., \& Koelling, R. A. Conditioned aversion to saccharin resulting from exposure to gamma irradiation. Science, 1955, 122, 157-158.

Parker, L., Failor, A., \& Weidman, K. Conditioned preferences in the rat with an unnatural need state: Morphine withdrawal. Joumal of Comparative and Physiological Psychology, 1973 , 82, 294-300.

Stolerman, I. P., \& Kumar, R. Preferences for morphine in rats: Validation of an experimental model of dependence. Psychopharmacologia, 1970, 17, 137-150.

Ternes, J. W. Induced preference for morphine in rats. The Bulletin of the Psychonomic Society, 1975, in press.

Wikler, A. Opiate addiction. Springfield, Ill: Thomas, 1953.

Winer, B. J. Statistical principles in experimental design. New York: McGraw-Hill, 1962.

(Received for publication November 6, 1974.) 